Tsaqofiya : Jurnal Pendidikan Bahasa dan Sastra Arab

Vol. 3 No. 2, Juli 2021, 235-251

P-ISSN : 2685-7022, E-ISSN : 2685-7103

DOI : https://doi.org/10.21154/tsaqofiya.v3i2.79

\title{
KALIMAT KONDISIONAL DALAM BAHASA ARAB DAN BAHASA INGGRIS (ANALISIS KONTRASTIF BENTUK DAN FUNGSI)
}

\author{
Muhammad Jauzil Bahraen', Muhammad Yusuf ${ }^{2}$ \\ Universitas Islam Negeri Sunan Kalijaga Yogyakarta \\ 1bahraenozil@gmail.com,2elyusuf03@gmail.com
}

\section{Abstract}

Conditional sentences are part of the syntactic system that exists in Arabic and English. In general, the provisions relating to conditional sentences in the two languages have similarities and differences. This study seeks to identify more deeply related to this matter by way of contrasting it. The subject matter relates to the similarities and differences in the form and function of conditional sentences in Arabic and English. This study is a literary style that optimizes related literature to discuss the object of research. This study formulates that the similarity in the form and function of conditional sentences in Arabic and English, namely: it can be stated implicitly, has two-sentence forms, has clear rules, has the same primary components, can be used to convey open and conjectural conditions. The differences are: Arabic markers are more varied, the characteristics of conditional sentences in Arabic focus on the markers while in English it is more on tenses, the construction of conditional sentences in Arabic is more varied than in English.

Keywords: Conditional Sentences, Arabic, English, Contrastive Analysis

\section{Abstrak}

Kalimat kondisional merupakan bagian dari sistem sintaksis yang ada dalam bahasa Arab dan bahasa Inggris. Lazimnya, ketentuan yang berkaitan dengan kalimat kondisional dalam kedua bahasa tersebut terdapat persamaan dan perbedaan. Penelitian ini berupaya untuk mengidentifikasi lebih dalam berkaitan dengan hal tersebut dengan cara mengkontraskannya. Adapun pokok masalah berkaitan dengan persamaan dan perbedaan bentuk dan fungsi kalimat kondisional dalam bahasa Arab dan bahasa Inggris. Kajian ini bercorak kepustakaan yang mengoptimalkan literatur terkait untuk membahas objek penelitian. Kajian ini merumuskan bahwa persamaan bentuk dan fungsi kalimat kondisional dalam bahasa Arab dan bahasa Inggris yaitu: dapat dinyatakan secara implisit, mempunyai dua bentuk kalimat, mempunyai aturan yang jelas, mempunyai komponen primer yang sama dan dapat digunakan untuk menyampaikan kondisi yang bersifat terbuka dan dugaan. Adapun perbedaannya adalah: penanda bahasa Arab lebih variatif, karakteristik kalimat kondisional dalam bahasa Arab menitikberatkan pada penanda sementara dalam bahasa Inggris lebih kepada tenses, kontruksi kalimat kondisional dalam bahasa Arab lebih variatif dari bahasa Inggris.

Kata Kunci: Kalimat Kondisional, Bahasa Arab, Bahasa Inggris, Analisis Kontrastif 


\section{PENDAHULUAN}

Bahasa identik dengan intrumen yang difungsikan untuk mengekspresikan ide, maksud, gagasan, perasaan, dan sebagainya. Secara general, ada dua kategori yang lazim digunakan individu untuk berekspresi, yaitu pendekatan verbal dan non-verbal. Pendekatan verbal menitik beratkan pada penggunaan kata, baik secara lisan atau tulisan untuk mengekspresikan sesuatu. Sementara non-verbal adalah pendekatan ekspresi yang menekankan pada penyampaian pesan dengan tanpa kata. Dengan kata lain, pendekatan ini bertumpu pada segala aktivitas individu yang dengan disengaja disampaikan untuk ditafsirkan seperti gesture, warna, mimik wajah, body language, dan bahasa simbol yang lainnya. ${ }^{1}$

Pendekatan ekspresi secara verbal dominan digunakan manusia untuk berinteraksi dengan sesamanya. Hal itu dikarenakan lambang verbal secara fungsional lebih mudah digunakan dan lebih mudah difahami. Melalui kata-kata, manusia mengungkapkan perasaan, emosi, pemikiran, menyampaikan fakta, data, dan informasi. Dalam pendekatan ini, bahasa mempunyai peran strategis. Bahasa dalam konteks ini diartikan sebagai lambang verbal yang mempunyai struktur formal yang lazim. ${ }^{2}$ Optimalisasi ekspresi verbal dalam tindak komunikasi oleh seseorang memerlukan kapasitas dan kapabilitasnya dalam memahami struktur formal bahasa verbal. Lazimnya komponen dari bahasa verbal tersebut terdiri dari fonologi, morfologi, sintaksis, dan semantik. ${ }^{3}$ Penguasaan terhadap keempat aspek linguistik ini akan menentukan kecakapan seseorang dalam berkomunikasi dan berinteraksi dengan sesamanya.

Aspek sintaksis dalam kapasitasnya sebagai komponen linguistik merupakan seperangkat aturan yang bersinggungan secara langsung terhadap terbentuknya sebuah frasa, klausa, dan kalimat. Pada gilirannya kalimat inilah yang akan mentransfer pesan dari pembawa ke penerimanya. Dengan kata lain, kalimat tersebut mempunyai makna yang merupakan esensi seorang individu berkomunikasi atau berkespresi. Bertitik dari hal tersebut, dapat diketahui urgensi dari menelaah dan menguasai aspek sintaksis dari sebuah bahasa. Dalam kajian linguistik, salah satu aturan yang berkaitan dengan aspek sintaksis adalah hubungan makna. Keterkaitan

\footnotetext{
1 Tri Indah Kusumawati, “Komunikasi Verbal dan Non-verbal”, Al-Irsyad: Jurnal Pendidikan dan Konseling Vol. 06, No. 02, 2016. , 84-85

${ }^{2}$ Ibid

3 Saida Gani dan Berti Arsyad, "Kajian Teoritis Struktur Internal Bahasa: Fonologi, Morfologi, Sintaksis, dan Semantik", 'Ajamiy: Jurnal Bahasa dan Sastra Arab, Vol. 07, No. 01, 2018. , 3.
} 
dua bagian dalam satu kalimat karena ada interelasi makna di dalamnya. Hubungan keduanya ibarat dua sisi mata uang yang tidak dipisahkan satu dengan yang lainnya. Dalam bahasa indonesia hubungan makna antar keduanya tersebut disebut satuan kondisional. Term tersebut besinonim dengan al-jumlah asy-syartiah ${ }^{4}$ dalam bahasa Arab dan kalimat pengandaian (conditional sentences) dalam bahasa Inggris. ${ }^{5}$

Kalimat kondisional merupakan salah satu unsur dalam ilmu gramatika yang mencitrakan gaya bahasa. Penguasaan secara komprehensif terhadapnya akan memudahkan seseorang untuk memahami jenis kalimat sehingga berpotensi mampu mengungkapkan makna yang terkandung di dalamnya. 6 Tulian ini hendak mengkaji kalimat kondisional dalam dua bahasa, yaitu Arab dan Inggris. Pemilihan keduanya sebagai objek penelitian didasarkan pada karakterisitik dan sejumlah label yang sedang melekat pada dua bahasa tersebut sehingga berimplikasi pada pengakuan skala Internasional terhadap eksistensi keduanya. Adapun pokok pembahasan dalam kajian ini nantianya akan menelaah aspek perbedaan dan persamaan gramatika kalimat kondisional dalam bahasa Arab dan bahasa Inggris.

Analisis kontrastif merupakan cabang dari linguistik mikro yang secara operasional mengkaji perbedaan dan persamaan dua sistem bahasa atau lebih. ${ }^{7}$ Secara terminologi analisis kontrastif merupakan kerangka kerja "bandingmembanding" dua gramatika bahasa atau lebih yang diorientasikan untuk menemukan persamaan dan perbedaan di dalamnya. Identifikasi terhadap kedua sistem bahasa tersebut berangkat dari kajian linguistik deskriptif, dan bukan linguistik historis. ${ }^{8}$ Hal tersebut sesuai dengan pendapat Yakut yang menyatakan bahwa analisisi kontrastif selalu identik dengan kerja membandingkan dua sistem bahasa atau lebih yang berbeda rumpun kebahasaannya. Sementara itu, Parera menyatakan bahwa kerja membandingkan dua sistem bahasa akan sulit, bila tidak boleh dikatakan mustahil, untuk mengkaji setiap elemen dan partikel di dalamnya. ${ }^{9}$ Oleh karenaya diperlukan spesifikasi tertentu. Dengan kata lain, pemilihan unsur dari

${ }^{4}$ Afnan Arummi, "Tinjauan Elipsis Pada Kalimat Kondisional Bahasa Arab”, Jurnal CMES 6 (2), 2013., 165

${ }^{5}$ Afnan Arummi, Kalimat Kondisional dalam Bahasa Arab (Temanggung: Armasta, 2019), 4.

6 Ibid. , 2.

7 Moh. Ainin, Analisa Bahasa Pembelajar Bahasa Arab sebagai Bahasa Asing: Kajian Analisis Kontrastif, Kesilapan dan Koreksi Kesilapan (Malang: Misykat,2011), 45.

8 Misdawati, "Analisis Kontrastif dalam Pembelajaran Bahasa”, 'Ajamiy: Jurnal Bahasa dan Sastra Arab, Vol. 8, No. 1, 2019. , 57.

${ }^{9}$ Jos Daniel Parera, Linguistik Edukasional: Metodologi Pembelajaran Bahasa, Analisis Kontrastif antar Bahasa dan Analisis Kesalahan Berbahasa (Jakarta: Erlangga, 1997), 112. 
subsistem dan kategori tertentu merupakan kerangka kerja mendasar analisis kontrastif.

Subsistem dalam satuan kondisional dalam konteks penelitian ini berkaitan dengan aspek fungsi dan bentuk kalimat kondisional dalam bahasa Arab dan bahasa Inggris. Penelaahan terhadap kedua aspek tersebut menjadi penting mengingat karakteristik yang berbeda dalam sistem bahasa Arab dan bahasa Inggris. Dalam konteks bahasa Arab misalnya, penanda kondisional di dalamnya sangat beragam dan mempunyai interelasi gramatika dengan kalimat syarat dan jawabnya. Sementara dalam bahasa Inggris, fungsi penanda hanya sebatas komponen dalam satuan kondisional. Adapun dalam konteks bentuk misalnya karakter dari kalimat kondisional yang diawali oleh partikel negasi, qod, ataupun saufa, hal yang seperti itu tidak ditemukan dalam sistem kalimat kondisional bahasa Inggris. ${ }^{10}$

Bertitik dari studi pendahuluan di atas, tulisan ini hendak mengkaji lebih dalam berkaitan dengan perbandingan dan persamaan fungsi dan bentuk dalam satuan kondisional bahasa Arab dan bahasa Inggris.

\section{METODE}

Penelitian bahasa pada dasarnya adalah pengkajian terhadap gejala-gejala kebahasaan yang eksis dalam masyarakat tutur. Gejala dalam masyarakat tutur tersebut yang coba penulis kumpulkan dan interpretasikan sehingga pada hilirnya akan ditemukan kaidah-kaidah kebahasaan yang bersifat spesifik pun universal. Secara operasional, penulis akan mengumpulkan gejala kebahasaan yang berkaitan dengan subsistem dalam kalimat kondisional berupa bentuk dan fungsi dalam bahasa Arab dan bahasa Inggris. Selanjutnya penulis akan menginterpretasi atau memberikan makna terhadap pokok pembahasan dengan menggunakan pendekatan kontrastif yang berupaya mengidentifikasi perbedaan dan persamaan dalam pokok pembahasan. Dengan kata lain, kajian ini mempunyai corak kepustakaan dan interpretasinya menggunakan kerangka kerja analisis kontrastif.

${ }^{10}$ Afnan Arummi, "Konstruksi Apodosis dalam Susunan Kondisional Bahasa Arab: At Tarkib A'sy-Syarthiy", Prosiding Konferensi Nasional Bahasa Arab 11, Jurusan Sastra Arab Fakultas Sastra Universitas Negeri Malang: 15 Oktober 2016, 511. 


\section{PEMBAHASAN}

\section{Kalimat Kondisional dalam Linguistik Umum}

Kalimat kondisional identik dengan sebuah kalimat yang mempunyai dua bagian di dalamnya, bagian pertama dikenal dengan istilah kalimat syarat dan bagian kedua disebut jawab syarat. Kedua bagian dalam kalimat kondisional mempunyai interelasi makna yang tidak dapat dipisah satu dengan yang lainnya. Bagian pertama menentukan berlaku pun tidaknya sesuatu yang berada pada bagian kedua, sementara bagian kedua merupakan afirmasi dari ada atau tidaknya bagian pertama. Dengan kata lain bagian kedua merupakan komponen yang eksistensinya menentukan hukum yang diterangkan bagian pertama. Dalam linguistik umum, kalimat kondisional disebut sebuah kalimat yang terdiri dari prostasis dan apodosis, dimana kalimat utamanya mengungkapkan apa yang dimunculkan atau dihadirkan dari persyaratan tersebut. ${ }^{11}$

Kridalaksana mendefinisikan kalimat kondisional dengan mengkategorisasikan kedalam tiga pengertian yang saling terintegrasi, yaitu: 1) kalimat yang terdiri dari prostasis dan apodosis; 2) kalimat yang terdiri dari klausa yang mengungkapkan syarat pengandaian; 3) kalimat berbentuk verba yang mengungkapkan atau mengekspresikan pengandaian atau hipotesa. Sementara itu, Tumijo dan Riyanto menyatakan bahwa kalimat kondisional dicitrakan dengan gaya bahasa yang dioptimalkan untuk mengekspresikan pengandaian pada harapan, rencana, keinginan, dan lainnya yang bersifat mustahil pun sebaliknya, dan pengandaian yang kontras dengan fakta ketika kalimat pengandaian tersebut diekspresikan. Al-Khuli menyatakan bahwa satuan kondisional merupakan kalimat yang terdiri dari penanda, syarat, dan jawab, di mana ketiganya saling melengkapi satu sama lain. ${ }^{12}$

\section{Kalimat Kondisional dalam Bahasa Arab}

Dalam bahasa Arab kalimat kondisional disebut dengan istilah jumlah syartiyah yang notabenenya mempunyai tiga komponen, yaitu fi'il syarat, jawab syarat, dan adat syarat. Contoh: كيفما تقل أقل . Pada contoh tersebut كيفا merupakan adatusy syarti (penanda); تقل merupakan kalimat syarat (prostasis); dan أقل merupakan kalimat jawab (apodosis). ${ }^{13}$ Ketentuan lain yang berkaitan dengan jumlah syartiyah akan

\footnotetext{
${ }^{11}$ Afnan Arummi, Kalimat Kondisional dalam Bahasa Arab, . 2.

12 Ibid, . 3.

${ }^{13}$ Ali Asrun Lubis, “Kalimat Kondisional dalam Bahasa Arab”, Jurnal Thariqah Ilmiah Vol. 1, No. 2 , 2014. , 90.
} 
diuraikan berdasarkan komponen yang membentuknya, yaitu penanda, syarat dan jawab.

\section{Adat syarat}

Posisi adat syarat dalam sistem kondisional bahasa Arab mempunyai dampak signifikan pada pembentukan jumlah syartiyah, khususnya pada kata kerja (verba/fi'il) yang berposisi setelahnya. Adat syarat dalam hal ini selain mempunyai kapasitas untuk menghubungkan dua klausa secara maknawi, juga punya kapasitas untuk memberikan dampak pada akhiran harakat setiap kata kerja setelahnya (yang berposisi sebagai prostasis dan apodosis).

Musthafa Al-Ghalayaini dalam bukunya menjelaskan bahwa Adat syarat إن ، إذما، من، ما، مهما، منى، أيان، أنّى، أين، : secara keseluruhan ada delapan belas, yaitu 14 Dalam perspektif Barakat, delapan belas Adat syarat tersebut dikanalisasi menjadi tiga golongan. Hal ini berdasar pada tinjauannya pada pengaruh Adat syarat pada verba setelahnya. Berikut uraian deskriptif tiga kanalisasi Adat syarat dalam tinjauan Barakat:

a. Penanda kondisional apokopatif (yang men-jazm-kan)

Adat syarat jenis ini merupakan penanda yang dapat merubah i'rab kalimat fi'il setelahnya menjadi jazm. Adat syarat jenis ini terdiri dari partikel dan nomina. Partikel dalam kategori ini ada dua, yaitu إذما dan Sementara dalam kategori nomina terdiri dari: من، ما، أي، مهما، أيّانا، متى، أين، أنّى، حيثما.

b. Penanda kondisional non-apokopatif (tidak men-jazm-kan)

Adat syarat jenis ini merupakan penanda kondisional yang tidak bisa merubah i'rab kalimat verba yang berposisi setelahnya. Adat syarat jenis juga terdiri dari partikel dan nomina. Partikel dalam term ini beranggotakan لو، لو لا، إذا Sementara nomina dalam term ini merujuk pada .لوما.

c. Adat syarat yang mengandung makna kondisional

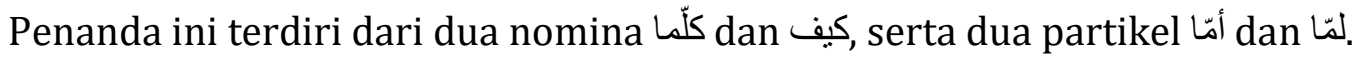

\section{Fi'il Syarat}

Fi'il syarat merupakan komponen primer dalam satuan kondisional yang menjadi penentu terjadi atau tidaknya hukum yang berada pada kalimat setelahnya (jawab). Fi'il syarat mempunyai beberapa ketentuan di dalamnya, yaitu:

14 Muh. Zuhri dkk, Tarjamah Jami'ud Durusil Arabiyah II-III (Semarang: CV. Asy-Syifa', 1992), 
1) terdiri atas fi'il mutashorrif; 2) harus dalam bentuk kalimat berita; c) tidak disertai dengan salah satu dari سوف، س، مانفى، لن، قد di dalamnya.

Fi'il Syarat dalam bahasa Arab dapat berupa klausa verbal, klausa nominal, klausa preposisional, protasis bertingkat, protasis yang dilesapkan, dan protasis tanpa penanda kondisional. ${ }^{15}$

\begin{tabular}{|c|c|}
\hline Contoh & Jenis Protasis \\
\hline إن أحسنتم أحسنتم لأنفسكم & Klausa verbal \\
\hline فلولا فضل الله عليكم ورحمته لكنتم من الخاسرين & Klausa nominal \\
\hline أمّا في المسجد فرجال يعرفون طريقَ الحقّ & Klausa preposisi \\
\hline فإمّا يأتينّكم منّي هدًى فمن تبع هداي فلا خوف & Protasis bertingkat \\
\hline إن تتواضع تحمد وإلا تذم (وإلاً تتواضع....) & Protasis yang dilesapkan \\
\hline إتّقى الله امرؤ وفعل خيرا يثبت عليه (إن اتّى.....) & $\begin{array}{l}\text { Protasis tanpa penanda } \\
\text { kondisional }\end{array}$ \\
\hline
\end{tabular}

\section{Jawab Syarat}

Afnan Arummi menjelaskan bahwa apod (Jawab Syarat) dalam susunan kalimat kondisional terdiri dari sebuah V, baik yang berasal dari Vp maupun Vi. Untuk itu, $\mathrm{V}$ dalam apod dapat dijazamkan. Namun apabila apod tidak terdiri dari sebuah V, maka wajib diawali dengan partikel $f a^{\prime}, i d z a$, atau idzan. Dengan adanya partikel-partikel ini, maka unsur dalam apod yang bukan berasal dari V, boleh dijazamkan dan dapat diartikan serta dimaknai sebagai jawaban dari kalimat kondisional yang disebut apod. ${ }^{16}$

Apodosis dalam bahasa Arab dapat berupa klausa verbal, klausa nominal, jumlah thalabiyah, fi'il jamid, apod yang didahului partikel negasi, apod yang didahului oleh 'qod', apod yang didahului oleh 'sin' dan 'saufa', apod yang didahului oleh 'rubba', apod yang didahului oleh partikel juratif, apod yang didahului oleh nomina verbal, apod yang bermakna ketakjuban. ${ }^{17}$

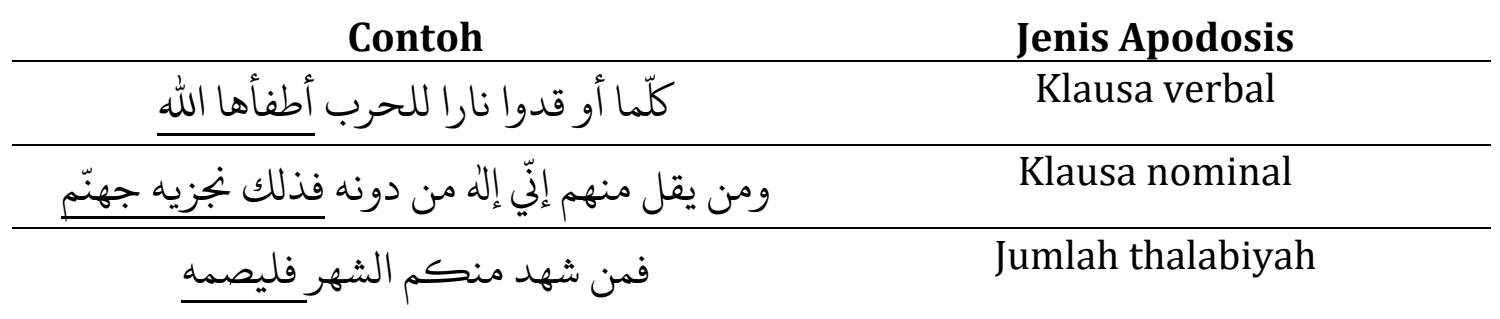

${ }^{15}$ Afnan Arummi, Kalimat Kondisional dalam Bahasa Arab, . 188.

${ }^{16}$ Afnan Arummi, Kalimat Kondisional dalam Bahasa Arab, . 128-129

17 Ibid, . 189. 


\begin{tabular}{|c|c|}
\hline إن تبدوا الصدقات فنعمّا هي & Fi'il jamid \\
\hline ومن يبتغ غير الإسلام دينا فلن يقبل منه & $\begin{array}{l}\text { Apod yang didahului partikel } \\
\text { negasi }\end{array}$ \\
\hline إنّه من يشرك بالله فقد حرّم الله عليه الجنّة & Apod yang didahului 'qod' \\
\hline وإن تعاسرتم فسترضع له أخرى & Apod yang didahului 'sin' \\
\hline من يبادر أخاه بالمصلحة فربّما يكون ذلك خيرا & Apod yang didahului 'rubba' \\
\hline من عمل صالحا من ذكر أو أنثى وهو مؤمن فلنحيينّه & $\begin{array}{c}\text { Apod yang didahului partikel } \\
\text { juratif }\end{array}$ \\
\hline أيّان ما يتحدّث أستاذك فصه & $\begin{array}{c}\text { Apod yang didahului oleh nomina } \\
\text { verbal }\end{array}$ \\
\hline تاجين فلله درّه كريما & Apod yang bermakna ketakjuban \\
\hline
\end{tabular}

\section{Kalimat Kondisional dalam Bahasa Inggris}

Kalimat kondisional dalam bahasa Inggris disebut dengan kalimat pengandaian (conditional sentences) yang dapat dinyatakan dalam tiga tipe, yaitu: 1) future conditional sentences; 2) present conditional sentences; 3) past conditional sentences. ${ }^{18}$ Dalam perspektif yang lain, Sokah berpendapat bahwa kalimat kondisional dalam bahasa Inggris dinyatakan dalam: 1) kalimat kondisional terbuka (open condition); 2) kalimat kondisional dugaan yang tidak mungkin (improbable, unlikely); dan 3) kalimat kondisional yang mustahil. Perbedaan pendapat di atas hanya terletak dalam masalah pengidentifikasiannya saja, namun secara substansial sama. ${ }^{19}$

\section{Kalimat Kondisional Terbuka (Future Conditional Sentences)}

Kalimat kondisional tipe ini digunakan untuk mengungkapkan atau mengandaikan suatu keinginan, harapan, atau rencana yang masih mungkin bisa terjadi. Tipe ini dapat dirumuskan dalam dua bentuk sebagai berikut:

1) $($ If + Subject + Verb 1/ Verb-s/es (Present Tense $))+($ Subject + will + Verb +1 (Future Tense)). Contoh: If I have time, I will go to Jony's party; jika aku punya waktu, aku akan pergi ke pesta Jony. 55.

18 Tumijo dan Slamet Riyanto, 99,99\% Sukses TOEFL (Yogyakarta: Pustaka Widyatama, 2010),

19 Afnan Arummi, Kalimat Kondisional dalam Bahasa Arab, .4. Lihat juga dalam Attila Imre, "A Logical Approach to English Conditional Sentences", Journal of Romanian Literary Studies Issues No. 12, 2017. , 158 
2) $($ Subject + will + verb $+($ Future Tense $))+($ If + subject + verb $1 /$ verb - s/es $($ Present Tense)). Contoh: I will go to Johny's party if I have time; aku akan pergi ke pesta Jony jika aku punya waktu. ${ }^{20}$

Jika diperhatikan, klausa utama dalam dua contoh di atas yaitu kalimat jawabannya (I will go to Johny's party) merupakan future tense atau kata kerja dalam bentuk masa depan, sedangkan klausa syaratnya yaitu If a have time merupakan present tense atau kata kerja dalam bentuk sekarang. Klausa utama akan mungkin terjadi jika syaratnya terpenuhi. Dengan kata lain, peristiwa 'pergi' dalam 'I will go' akan terlaksana jika ada 'waktu' dalam 'if I have time'.

\section{Kalimat Kondisional Dugaan yang Tidak Mungkin (Present conditional sentences)}

Tipe kedua ini digunakan untuk mengungkapkan keinginan, harapan, atau rencana yang tidak terpenuhi, atau angan-angan yang bertentangan dengan fakta saat ini. Tipe ini dirumuskan dengan dua bentuk seperti berikut:

1) (If + subject + verb 2 (Past tense) $)+($ subject + would + verb 1 (past future tense)).

Contoh: If I had time, I would go to Johny's party; 'jika aku punya waktu, aku akan pergi ke pesta Jony'.

2) (Subject + would + verb 1 (Past future tense) $)+($ if + subject + verb 2 (Past tense)).

Contoh: I would go to Johny's party if I had time; 'aku akan pergi ke pesta Jony jika aku punya waktu'. ${ }^{21}$

Keinginan 'pergi ke pesta Jony' sudah tidak mungkin terjadi karena fakta saat ini 'aku tidak punya waktu'. Klausa utama dalam contoh kontruksi di atas merupakan bentuk past future tense dan klausa syaratnya atau if-clause-nya merupakan bentuk past tense. Dalam bentuk tipe ini, Sokah berpendapat bahwa past tense dalam if-clause bukan merupakan past tense dalam arti yang sebenarnya, sebab maksudnya adalah 'waktu kini' atau 'masa depan'. Jadi bila dikatakan 'if I had time, I would go to Johny's party' berarti 'if I had time now, I would go to Johny's party'. Bentuk kalimat dalam tipe ini merupakan kalimat khayalan atau dugaan

\footnotetext{
${ }^{20}$ Afnan Arummi, Kalimat Kondisional dalam Bahasa Arab, . 4. Lihat Juga dalam Bas Aarts, Sylvia Chalker, and Edmund Weiner, The Oxford Dictionary of English Grammar, Second Edition (United Kingdom: Oxford University Press, 2014), 87. Bandingkan dengan Attila Imre, "A Logical Approach to English Conditional Sentences”, Journal of Romanian Literary Studies Issues No. 12, 2017. , 158

${ }^{21}$ Ibid, . 5. Lihat juga dalam Attila Imre, "A Logical Approach to English Conditional Sentences", . 160.
} 
yang tidak terjadi sekarang, tapi kemungkinan hasilnya dapat dikhayalkan atau diperkirakan jika syarat tertentu dipenuhi.

Pada tipe ini, kata kerja bentuk be yang dipakai selalu were, apapun subjeknya. To be was tidak pernah digunakan. Misalnya: if I were rich, I would travel around the world; 'jika aku kaya, aku akan pergi keliling dunia'. Keinginan yang diungkapkan dalam kalimat pengandaian di atas sudah tidak mungkin terjadi, karena bertentangan dengan fakta saat ini. Kalimat pengandaian di atas memiliki arti: I am not rich, I am not going to travel around the world; 'aku tidak kaya, aku tidak akan pergi keliling dunia'.

\section{Kalimat Kondisional yang Mustahil (Past Conditional Sentences)}

Kalimat pengandaian tipe ini, digunakan untuk mengandaikan sebuah peristiwa, keinginan, harapan, atau rencana yang sudah tidak mungkin lagi terjadi, karena peristiwa yang sesungguhnya sudah terjadi di masa lampau. Tipe ini dapat dirumuskan sebagai berikut:

1) $($ If + subject + had + verb 3 (Past perfect tense $))+($ Subject + would/could $/ \mathrm{might}+$ have + verb 3 (Past future perfect tense)). Contoh: If she had got the money, she would have bought a car; 'jika dia telah mendapatkan uang, dia akan telah membeli mobil'.

2) $($ Subject + would/could/might + have + verb 3 (Past future perfect tense $))+($ If + subject + had + verb 3 (Past perfect tense)). Contoh: She would have bought a car if she had got the money; 'dia akan telah membeli mobil jika dia telah mendapatkan uang'.22

Contoh di atas memiliki fakta: She did not get the money so she did not buy a car; 'dia tidak mendapatkan uang sehingga dia tidak membeli mobil'.

Tipe ini juga bisa diungkapkan tanpa menggunakan if, yaitu dengan menggunakan pembalikan. Caranya, kata kerja bantu had diletakkan belakang subject dan kata if dihilangkan. Dapat dinyatakan dalam rumus berikut: (Had + subject + Verb 3) + (Subject + would/could/might + have + verb 3). Contoh: had she got the money, she would have bought a car.23

22 Ibid, . 6. Bandingkan dalam Attila Imre, "A Logical Approach to English Conditional Sentences", 162-164.

23 Ibid, . 6-7. 


\section{Analisis Kontrastif Bentuk dan Fungsi Kalimat Kondisional dalam Bahasa Arab dan Bahasa Inggris}

\section{Persamaan}

Untuk memudahkan seseorang dalam mengetahui suatu bahasa, diperlukan adanya pengetahuan tentang persamaan suatu bahasa dengan bahasa yang dibandingkan. Berikut ini akan diungkapkan mengenai persamaan kalimat kondisional dalam bahasa Arab dan bahasa Inggris baik dari segi bentuk dan fungsi.

\section{a. Persamaan dari segi bentuk}

a) Lazimnya kalimat kondisional dalam bahasa Arab dan bahasa Inggris dinyatakan secara eksplisit, dengan menggunakan partikel di dalamnya.

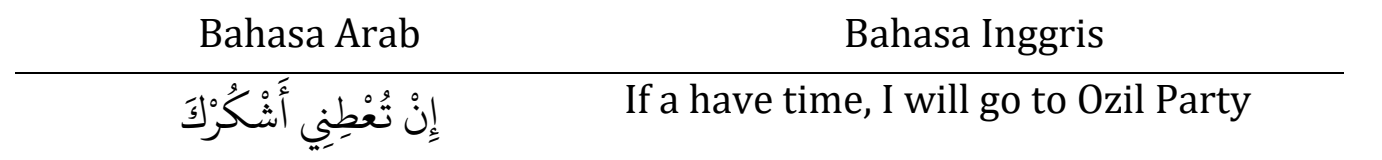

b) Kalimat kondisional dalam bahasa Arab dan bahasa Inggris dapat dinyatakan secara implisit, yaitu tanpa menggunakan partikel atau huruf syarat.

\begin{tabular}{cc} 
Bahasa Arab & Bahasa Inggris \\
\hline تكلّم بخير، وإلاً فاسكت & $\begin{array}{c}\text { Had I got married, I would have built a } \\
\text { house }\end{array}$
\end{tabular}

Keterangan: kalimat di atas Keterangan: kalimat di atas aslinya adalah aslinya adalah تكلّم بخير، وإن ل if I had got married, I would have built a house

c) Kalimat kondisional dalam bahasa Arab dan bahasa Inggris mempunyai dua bentuk bagian kalimat yang sama, yaitu terdapat bagian kalimat pertama dan bagian kalimat kedua. Bagian kalimat pertama disebut fi'il syarat dalam bahasa Arab dan protasis (if clause) dalam bahasa Inggris. Adapun bagian kalimat kedua disebut jawab syarat dalam bahasa Arab dan apodosis (main clause) dalam bahasa Inggris.

\begin{tabular}{ll}
\hline إنْ تُعْطِني أَشْكُرْكَ & If a have time, I will go to Ozil party \\
\hline
\end{tabular}

Keterangan: إن pada kalimat di atas merupakan penanda kondisional, sementara تُعْنِي merupakan kalimat pertama yang berposisi sebagai fi'il syarat.
Keterangan: if dalam kalimat di atas merupakan penanda kondisional, sementara a have time merupakan kalimat pertama yang berposisi sebagai if clause, sementara kalimat I wiil go to 
Adapun kalimat أَنْكُرْنَكَ merupakan Ozil party merupakan kalimat kedua kalimat kedua yang berposisi yang berposisi sebagai main clause sebagai jawab syarat

Perlu diketahui bahwasannya kedua bagian kalimat dalam kalimat kondisional saling berhubungan, artinya jika salah satu bagian kalimat hilang, maka pengertian dari kalimat itu menjadi tidak jelas. Sebab bila satu bagian kalimat lepas, maka akan timbul suatu pertanyaan. Dengan kata lain, hilangnya salah satu bagian dari kedua bagian kalimat tersebut menghilangkan karakter primer dari kalimat kondisional.

d) Bahasa Arab dan bahasa Inggris sama-sama beraturan dalam menyatakan kondisional terbuka dan dugaan. Dalam bahasa Inggris hal itu dapat diketahui dari waktu kata kerja (tense), bukan dari partikel. Sementara dalam bahasa Arab dengan menggunakan partikel. Kalimat kondisional duggan yang mungkin dinyatakan dengan 'in' dan kawan-kawannya. Dugaan yang tidak mungkin atau mustahil dinyatakan dengan 'law' dan kawankawannya, dan yang terbuka dapat dinyatakan dengan 'idzaa', 'lamma', dan 'kullama'.

Bahasa Arab Bahasa Inggris

\begin{tabular}{|c|c|}
\hline إذا فرغت فانصب & if you finish, you will hurry up \\
\hline ل ل و ذاكرت لنجحت & $\begin{array}{l}\text { If you had remembered, you would have } \\
\text { lucked }\end{array}$ \\
\hline إنْ تُعْطِنِي أَشْكُوَْكَ & If you gave me, I would thank you \\
\hline
\end{tabular}

Keterangan: Contoh-contoh di atas mengindikasikan bahwa baik bahasa Arab ataupun bahasa Inggris mempunyai aturan yang berbeda dalam menyatakan kalimat kondisional terbuka dan dugaan. Bahasa Arab lebih menitik beratkan pada partikel/nomina atau penanda kondisional yang menyertai sebuah kalimat kondisional, sementara dalam bahasa Inggris lebih menekankna pada tenses yang berada pada kalimat kondisional.

Berdasarkan keterangan di atas, dapat diketahui bahwa baik dalam bahasa Arab dan bahasa Inggris sama-sama mempunyai aturan dalam menyampaikan kalimat kondisional.

\section{b. Persamaan dari Segi Fungsi}

a) Kalimat kondisional dalam bahasa Arab dan bahasa Inggris mempunyai komponen primer yang berfungsi sama. Partikel berfungsi sebagai penanda kondisional, kalimat pertama berfungsi sebagai fi'il syarat dalam bahasa Arab dan condition dalam bahasa Inggris, sementara kalimat kedua berfungsi 
sebagai jawab syarat dalam bahasa Arab dan main clause dalam bahasa Inggris.

\begin{tabular}{|c|c|}
\hline Bahasa Arab & Bahasa Inggris \\
\hline إنْ تُعْطِنِي أَشْكُرْكَ & If you gave me, I would thank you \\
\hline
\end{tabular}

Keterangan: Contoh di atas mengindikasikan bahwa baik dalam bahasa Arab pun bahasa Inggris, kalimat kondisional mempunyai komponen primer sama yang berfungsi sebagai penanda kondisional, fi'il syarat atau if clause, dan jawab syarat atau main clause.

b) Kalimat kondisional dalam bahasa Arab dan bahasa inggris bisa difungsikan untuk menyampaikan sesuatu, keinginan, harapan, yang masih mungkin terjadi. Fungsi tersebut dijalankan oleh tipe kalimat kondisional terbuka.

\begin{tabular}{cc} 
Bahasa Arab & Bahasa Inggris \\
\hline إذا فرغت فانصب, you will hurry up & if you finish, you
\end{tabular}

c) Kalimat kondisional dalam bahasa Arab dan bahasa Inggris bisa difungsikan untuk menyampaikan sesuatu, keinginan, harapan, rencana, yang bertentangan dengan fakta saat ini. Hal tersebut difungsikan oleh tipe kalimat kondisional dugaan yang tidak mungkin (Present conditional sentences).

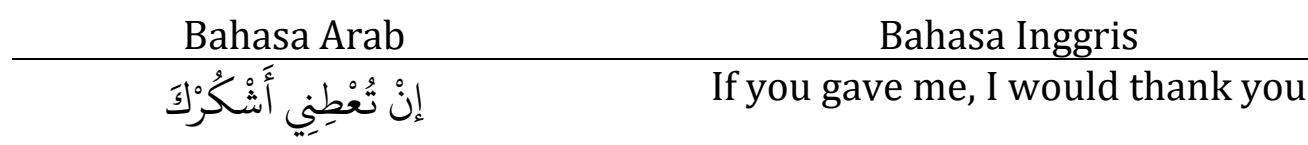

d) Kalimat kondisional dalam bahasa Arab dan bahasa Inggris sama-sama bisa difungsikan untuk menyampaikan sesuatu, keinginan, harapan, ide yang sudah tidak mungkin terjadi. Hal tersebut difungsikan oleh tipe kalimat kondisional dugaan yang mustahil (Past conditional sentences).

\begin{tabular}{cc} 
Bahasa Arab & Bahasa Inggris \\
\hline لو ذاكرت لنجحت & If you had remembered, you would have \\
lucked
\end{tabular}

\section{Perbedaan}

Di samping memiliki persamaan sebagaimana yang telah diuraikan di atas, kalimat kondisional dalam bahasa Arab dan bahasa Inggris tentu memiliki perbedaan-perbedaan yang menunjukkan karakternya masing-masing. Dalam konteks ini, akan dideskripsikan perbedaan kalimat kondisional dalam kedua bahasa tersebut berdasarkan pada bentuk dan fungsinya. 
TSAQOFIYA: Jurnal Pendidikan Bahasa dan Sastra, 3 (2), 2021

\section{a. Berdasarkan bentuk}

a) Bentuk penanda kondisional dalam bahasa Arab lebih beraneka dari penanda kondisional dalam bahasa Inggris. Penanda kondisional dalam bahasa Inggris identik dengan kata 'if' (partikel), sementara dalam bahasa Arab terdiri dari bentuk partikel dan nomina. Lebih lanjut, setiap bentuk penanda kondisional (partikel dan nomina) mempunyai beberapa kata yang bisa diposisikan sebagai penanda kondisional.

\section{Bahasa Arab}

Bahasa Inggris

$$
\begin{gathered}
\text { Partikel = in, idzma, law, lawla, dan lain } \\
\text { sebagainya. }
\end{gathered}
$$

Nomina $=$ man, ma, mahma, mata, ayyana, dan lain sebagainya.

b) Karakter kalimat kondisional terbuka dan dugaan dalam bahasa Arab dapat diidentifikasi melalui partikel yang ada di dalamnya. Kalimat kondisional dugaan yang mungkin dinyatakan dengan 'in' dan kawan-kawannya. Dugaan yang tidak mungkin atau mustahil dinyatakan dengan 'law' dan kawankawannya, dan yang terbuka dapat dinyatakan dengan 'idzaa', 'lamma', dan 'kullama'. Sementara karakter dari kalimat kondisional terbuka dan dugaan dalam bahasa Inggris dapat dilihat dari tenses yang berada di dalamnya. Tenses dalam kalimat kondisional terbuka berjenis future conditional sentences, sementara dalam dugaan tidak mungkin berjenis present conditional sentences, adapun dalam kalimat dugaan yang mustahil berjenis

\begin{tabular}{|c|c|}
\hline Bahasa Arab & Bahasa Inggris \\
\hline إذا فرغت فانصب & if you finish, you will hurry up \\
\hline لو ذاكرت لنجحت & If you had remembered, you would have lucked \\
\hline إنْ تُعْطِنِي أَُْكُرْكَ & If you gave me, I would thank you \\
\hline
\end{tabular}
past conditional sentences.

Keterangan: Contoh-contoh di atas mengindikasikan bahwa baik bahasa Arab ataupun bahasa Inggris mempunyai aturan yang berbeda dalam menyatakan kalimat kondisional terbuka dan dugaan. Bahasa Arab lebih menitik beratkan pada partikel/nomina atau penanda kondisional yang menyertai sebuah kalimat kondisional, sementara dalam bahasa Inggris lebih menekankna pada tenses yang berada pada kalimat kondisional. 
c) Konstruksi kalimat kondisional dalam bahasa Inggris identik dengan satu bentuk. Adapun dalam bahasa Arab, konstruksinya tidak terbatas pada satu bentuk saja, namun sangat beragam variannya. Hal ini dapat dibuktikan dengan masuknya unsur-unsur lain sebagai bagian dari unsur pembentuk kalimat kondisional bahasa Arab, seperti jumlah thalabiyyah, partikel juratif, partikel interogatif, , dan partikel negasi.

\begin{tabular}{|c|c|}
\hline Contoh & Jenis Varian \\
\hline فمن شهد منكم الشهر فليصمه & Jumlah Thalabiyah \\
\hline من عمل صالحا من ذكر أو أنثى وهو مؤمن & Partikel Juratif \\
\hline وإن يخذلكم فمن ذا الذي ينصركم من بعده & Partikel Interogatif \\
\hline ومن يبتغ غير الإسلام دينا فلن يقبل منه & Partikel Negasi \\
\hline
\end{tabular}

d) Kalimat kondisional dalam bahasa Arab mempunyai bentuk klausa bertingkat. Hal ini tidak ditemukan dalam bahasa Inggris.

\begin{tabular}{cc} 
Contoh & Keterangan \\
\hline فإمّا يأتينّكم منّي هدًى فمن تبع هداي فلا خوف $\quad$ Protasis bertingkat
\end{tabular}

\section{b. Berdasarkan fungsi}

a) Penanda kondisional dalam bahasa Inggris terdiri dari partikel yang hanya berfungsi sebagai penanda dan tidak mempunyai pengaruh dengan if clause atau main clause. Dengan kata lain, fungsi 'if' hanya sebatas menghubungkan dua unsur klausa. Sementara dalam bahasa Arab, partikel atau nomina yang diposisikan sebagai penanda kondisional selain menghubungkan dua unsur klausa, juga mempunyai pengaruh yang signifikan dalam perubahan I'rab setiap verba yang terdapat pada masing-masing klausa. Pengaruh tersebut tidak terlepas dari fungsi masing-masing penanda yang dapat diklasifikasikan menjadi tiga macam, yaitu penanda kondisional apokopatif (menjazmkan), penanda kondisional non apokopatif (tidak menjazmkan), dan penanda yang mengandung makna kondisional.

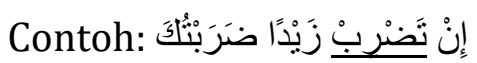

b) Tenses dalam kalimat kondisional bahasa Arab tidak berfungsi sebagaimana dalam bahasa Inggris. Dalam bahasa Arab, tenses tersebut bisa dirubah atau diartikan dengan disesuaikan kepada penanda kondisional yang menyertainya. Misalnya, bila tenses menunjukkan masa sekarang tetapi partikelnya menunjukkan dugaan (seperti 'law'), maka hal itu dapat dirubah 
menjadi masa lampau. Sebaliknya, bila tensesnya masa lampau maka dapat dirubah menjadi masa depan klaw dimasuki oleh partikel 'idza'.

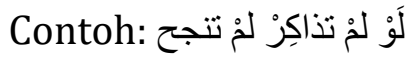

\section{Kesimpulan}

Persamaan kalimat kondisional dalam bahasa Arab dan bahasa Inggris dalam segi bentuk yaitu: a) umumnya disampaikan secara eksplisit, kendati pada beberapa kondisi dapat dinyatakan secara implisit; b) mempunyai dua bentuk kalimat, yang pertama disebut fi'il syarat dalam bahasa Arab dan if clause dalam bahasa Inggris. Adapun kalimat kedua disebut jawab syarat dalam bahasa Arab dan main clause dalam bahasa Inggris; c) mempunyai aturan yang jelas dalam menyampaikan kondisional terbuka dan dugaan. Adapun persamaan dari segi fungsi yaitu: a) mempunyai komponen primer yang berfungsi sama dalam konteks penanda kondisional, fi'il syarat atau if clause, dan jawab syarat atau main clause; b) keduaanya bisa digunakan untuk menyampaikan sesuatu, keinginan, harapan, ide yang bersifat terbuka dan dugaan.

Perbedaan kalimat kondisional dalam bahasa Arab dan bahasa Inggris dalam segi bentuk yaitu: a) penanda kondisional dalam bahasa Arab lebih variatif daripada dalam bahasa Inggris; b) karakter bentuk kalimat kondisional dalam bahasa Arab diidentifikasi dari penanda kondisional, sementara dalam bahasa Inggris menggunakan tenses; c) konstruksi kalimat kondisional dalam bahasa Arab lebih variatif daripada dalam bahasa Inggris; d) dalam bahasa Arab kalimat kondisional mempunyai bentuk klausa bertingkat, sementara dalam bahasa Inggris tidak. Adapun perbedaan dari segi fungsi yaitu: a) penanda kondisional dalam bahasa Arab mempunyai pengaruh besar pada I'rab fi'il syarat dan jawab syarat dalam bahasa Arab, sementara dalam bahasa Inggris tidak; b) tenses dalam kalimat kondisional bahasa Arab tidak berfungsi sebagaimana dalam bahasa Inggris yang digunakan untuk menentukan bentuk kalimat kondisional.

\section{DAFTAR PUSTAKA}

Aarts, Bas, and Sylvia Chalker, and Edmund Weiner. The Oxford Dictionary of English

Grammar, Second Edition. United Kingdom: Oxford University Press. 2014

Ainin, Moh. Analisa Bahasa Pembelajar Bahasa Arab sebagai Bahasa Asing: Kajian Analisis Kontrastif, Kesilapan dan Koreksi Kesilapan. Malang: Misykat. 2011 
Arummi, Afnan. "Tinjauan Elipsis Pada Kalimat Kondisional Bahasa Arab”. Jurnal CMES Vol. 6, No. 2. 2013.

. Kalimat Kondisional dalam Bahasa Arab. Temanggung: Armasta. 2019

. "Konstruksi Apodosis dalam Susunan Kondisional Bahasa Arab: At Tarkib

A’sy-Syarthiy“. Prosiding Konferensi Nasional Bahasa Arab 11, Jurusan Sastra Arab Fakultas Sastra Universitas Negeri Malang: 15 Oktober 2016.

Gani, Saida dan Berti Arsyad. "Kajian Teoritis Struktur Internal Bahasa: Fonologi, Morfologi, Sintaksis, dan Semantik". 'Ajamiy: Jurnal Bahasa dan Sastra Arab, Vol. 07, No. 01. 2018.

Imre, Attila. "A Logical Approach to English Conditional Sentences". Journal of Romanian Literary Studies Issues No. 12. 2017.

Kridalaksana, Harimurti. Kamus Linguistik. Jakarta: Gramedia Pustaka Utama. 1993

Kusumawati, Tri Indah. "Komunikasi Verbal dan Non-verbal". Al-Irsyad: Jurnal Pendidikan dan Konseling Vol. 06, No. 02. 2016.

Lubis, Ali Asrun. "Kalimat Kondisional dalam Bahasa Arab". Jurnal Thariqah Ilmiah Vol. 1. No. 2. 2014.

Misdawati. "Analisis Kontrastif dalam Pembelajaran Bahasa". 'Ajamiy: Jurnal Bahasa dan Sastra Arab, Vol. 8, No. 1. 2019.

Nur, Tajudin. "Analisis Kontrastif dalam Studi Bahasa". Arabi: Journal of Arabic Studies. Vol. 1. No. 2. 2016.

Parera, Jos Daniel. Linguistik Edukasional: Metodologi Pembelajaran Bahasa, Analisis Kontrastif antar Bahasa dan Analisis Kesalahan Berbahasa. Jakarta: Erlangga. 1997

Tarigan, Henry Guntur. Pengajaran Analisis Kontrastif Bahasa. Bandung: Angkasa. 2009

Tumijo dan Slamet Riyanto. 99,99\% Sukses TOEFL. Yogyakarta: Pustaka Widyatama. 2010

Zuhri, Muh. Dkk. Tarjamah Jami'ud Durusil Arabiyah II-III. Semarang: CV. Asy-Syifa'. 1992. 